\title{
Lateral Horn of the Spinal Cord
}

National Cancer Institute

\section{Source}

National Cancer Institute. Lateral Horn of the Spinal Cord. NCI Thesaurus. Code C32938.

An area of grey matter in the thoracic region of the spinal cord forming a laterally projecting triangle from the center of either side of the spinal cord. 